\title{
Expression of a Single, Host-Specific, Bacterial Pathogenicity Gene in Plant Cells Elicits Division, Enlargement, and Cell Death
}

\author{
Y. P. Duan, ${ }^{1}$ A. Castañeda, ${ }^{1}$ G. Zhao, ${ }^{1}$ G. Erdos, ${ }^{2}$ and D. W. Gabriel ${ }^{1}$ \\ ${ }^{1}$ Department of Plant Pathology, and ${ }^{2}$ The Biotechnology Program, University of Florida, Gainesville 32611, \\ U.S.A. \\ Accepted 5 February 1999.
}

\begin{abstract}
A fundamental question about microbial pathogens is how they elicit host-specific symptoms. We report here that expression of a single gene from a plant-pathogenic bacterium in plant cells elicits host-specific symptoms diagnostic of the disease caused by the pathogen. Expression of pthA from Xanthomonas citri in citrus cells is sufficient to cause division, enlargement, and death of host cells. Since elicitation of these symptoms depends on a functional type III protein secretion system in $X$. citri, we deduce that the PthA protein is a specific plant signal, its site of action is inside the plant cell, and it is a major determinant of host range.
\end{abstract}

Additional keywords: avirulence, citrus canker, NLS, nuclear localization, virulence.

The molecular basis of disease epidemics and the identification of factors determining disease severity, symptoms, and host range are subjects of intense interest to microbial pathologists. Plant diseases are useful for such molecular studies because both host and pathogen are often genetically tractable. Plant pathogens are also particularly useful for studies involving host range, because some pathogenic genera, such as the bacterial genus Xanthomonas, consist of variants that can attack species of nearly all major groups of higher plants (Starr 1983). Despite the wide collective host range of the genus Xanthomonas, individual strains that cause serious diseases are highly restricted in host range. For example, strains of Xanthomonas citri cause such a severe canker disease on citrus worldwide that the pathogen is quarantined and subject to eradication in many countries. Fortunately, the only known hosts of the pathogen are in the Rutaceous (citrus) family, and the pathogen does not cause cankers on other plants, even in artificial inoculations. What accounts for its ability to attack citrus so severely and specifically?

$X$. citri enters its hosts naturally by rain splash through stomata and grows in the abundant intercellular space of the spongy mesophyll; large pustules or cankers are then formed on leaves, stems, and fruit as the pathogen induces cell enlargement (hypertrophy), division (hyperplasia), and, ulti-

Corresponding author: D. W. Gabriel; E-mail: gabriel@ biotech.ufl.edu mately, death (necrosis) among contacted host cells (Swarup et al. 1991; Fig. 1). Eventually, the epidermis is ruptured, allowing massive bacterial egress to the plant surface (Fig. 1), where bacteria are readily available for rain splash and repeated infection cycles. Other xanthomonads can cause mild leaf spots on citrus, but lack the ability to rupture the epidermis and form the hyperplastic cankers that are diagnostic of citrus canker disease (Gabriel et al. 1989; Swarup et al. 1991). The citrus leaf spots are much less serious diseases, and are much less efficient in dissemination and spread on citrus (Graham and Gottwald 1991). Therefore, the ability to rupture the citrus epidermis is a major factor in both the severity of the disease and in its epidemiology.

A gene for pathogenicity, $p t h A$, is necessary for $X$. citri to cause citrus canker disease; insertion of $p$ thA cloned on pZit45 into other xanthomonads confers the ability to rupture the citrus epidermis and elicit cankers on citrus (Swarup et al. 1991). Since (i) this ability also requires a functional type III protein secretion system, (ii) crude protein preparations containing PthA failed to elicit symptoms, and (iii) $p t h A$ encodes functional nuclear localization signal (NLS) sequences, it therefore appeared likely that PthA functioned inside the plant cell (Yang and Gabriel 1995a). In order to determine the direct effect(s) of expression of pthA on plants in the absence of the pathogen, we used two methods to transiently express the gene in plant cells. We report here that expression of pthA in citrus cells is sufficient to elicit the symptoms diagnostic of citrus canker disease: hypertrophy, hyperplasia, and necrosis (see Figures 2 and 3).

Transient expression of pthA in citrus leaves induced small, raised cankers on sweet orange leaf surfaces that first became visible beginning 3 days after particle bombardment and 7 days after Agrobacterium tumefaciens inoculation. Control bombardments and A. tumefaciens inoculations with the expression vector alone showed no evidence of cankers or canker-associated symptoms. For particle bombardment, leaves were surface sterilized and bombarded with tungsten particles coated with DNA as described by Gray et al. (1994). The treated leaves were placed on Murashige and Skoog medium (Gibco BRL, Grand Island, NY) and incubated at $22^{\circ} \mathrm{C}$ under $16 \mathrm{~h}$ of light. For A. tumefaciens delivery, clones were mobilized into strain GV2260 with triparental matings and inocu- 
lated into citrus leaves as described (Kapila et al. 1997). Semithin sections of resin-embedded tissue were stained with toluidine blue. Cell division and cell enlargement were caused when pthA was delivered to citrus cells by either method, and the symptoms elicited were qualitatively typical of the symptoms induced by control $X$. citri inoculations, although $X$. citri induced much larger lesions (compare Figures 1 and 2). These quantitative differences are likely due to relatively inefficient gene transfer and/or gene expression, as well as non-uniform gene transfer to cells in a target area in the transient expression methods. It is also possible that additional pathogenicity factors from $X$. citri are needed to enhance the symptoms triggered by the action of $p t h A$.

No cankers were elicited on citrus in transient expression assays in which another member of the gene family, avrb6, was substituted for $p t h A$ on the same vectors (Table 1; Fig. 3). avrb6 is $97 \%$ identical to pthA in DNA sequence and was cloned from $X$. campestris pv. malvacearum (the cotton blight pathogen; Yang and Gabriel 1995b). Expression of avrb6::uidA in citrus cells was confirmed by $\beta$-glucuronidase (GUS) assays with pYD12.22. (Translational fusion of $p t h A$ with uidA on pYD12.9 showed GUS expression levels similar to those on pYD12.22 [data not shown], and did not affect the canker phenotype, which was comparable to pYD12.5.)

Progressive development of necrotic tissue was also observed in these transient expression assays in sweet orange, similar to control inoculations with $X$. citri but delayed and greatly reduced (Fig. 2B, D). Transiently expressed pthA caused cell death and necrotic tissue development as lesions aged, with necrosis becoming apparent 2 weeks following particle bombardment and 3 weeks following A. tumefaciens delivery. $X$. citri caused necrotic tissue development beginning after 8 days on sweet orange. Since the necrotic tissue developed following particle bombardment (in the absence of any bacteria) and was not observed in control bombardments, the necrosis was induced by expression of pthA and not by wounding or the action of bacterial enzymes or other inducers. These data strongly indicate that $p t h A$ causes programmed cell death (PCD) in citrus, in addition to cell division and cell enlargement. Inducing cell death in compatible interactions is thought to be important in providing nutrients for microbial pathogens, particularly after release onto the leaf surface (Greenberg 1997). Inducing PCD may be essential for high levels of growth of $X$. citri, since mutations of pthA in $X$. citri significantly reduce pathogen growth in planta (Swarup et al. 1991). Since $p t h A$ is citrus specific (see below) and causes cell death, if $p t h A$ thereby obtains enough nutrients to support high levels of growth in citrus, then pthA is a primary determinant of host range on citrus.

Finally, rupture of the citrus epidermis was observed when pthA was delivered by $A$. tumefaciens, although it was greatly reduced, compared with the $X$. citri controls (Figs. 1 and 2B, D). This suggests that the eruption force may come from the growth and physical expansion of bacterial population in planta and, in the case of $X$. citri, additional expansion may be caused by the hydration of xanthan gum produced by these bacteria. The proteases, lipases, and pectinases that are produced by X. citri (Gabriel et al. 1989) may also contribute to the symptoms by degrading cell walls and other cellular components.

The pathogenic symptoms directly elicited by $p t h A$ expression in citrus cells were host specific. In transient expression assays of $p t h A$ in tobacco, bean, and cotton, no canker phenotype was observed. Instead, a rapid necrotic reaction known as a hypersensitive response (HR) phenotype was usually observed (see for example Figure 4); however, in both cotton and bean there was evidence of cultivar-specific differences in the strength and timing of the necrotic reactions, some of which appeared quite weak (data not shown). These observations are consistent with published results of transferring pthA into xanthomonads that are pathogenic to plant hosts other than citrus; when placed in bean-specific or cotton-specific xanthomonads that are then inoculated on their respective hosts, $p$ thA causes a reduction of symptoms on all susceptible cultivars and also a cultivar-specific HR (Swarup et al. 1992). Pathogen genes that elicit an HR are called avirulence (avr) genes. pthA is therefore a citrus-specific pathogenicity ( $p t h)$ gene as well as an $a v r$ gene in plants other than citrus. Since the hypertrophy and hyperplasia caused by $p t h A$ that lead to epidermal rupture are host specific and epidemiologically significant, pthA contributes to host range by causing hypertrophy and hyperplasia, in addition to its possible involvement in increasing nutrient availability through cell death.

No previous studies have reported that microbial pathogenicity genes that are normally expressed in the microbe can elicit pathogenic symptoms when expressed inside plant cells.
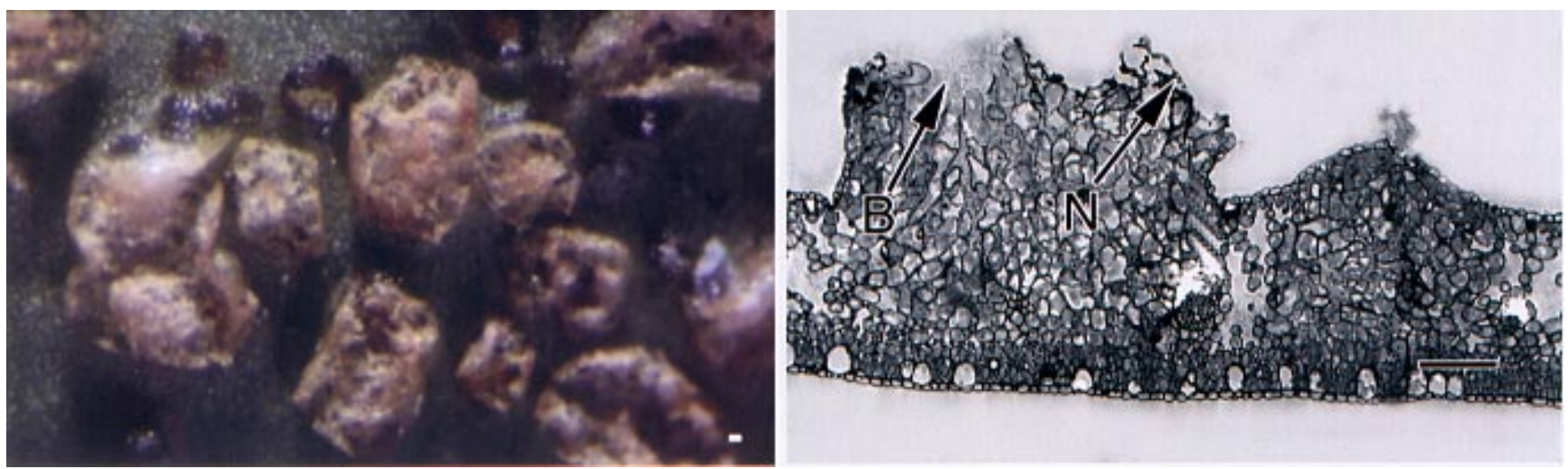

Fig. 1. Phenotype elicited on Citrus sinensis (sweet orange) by Xanthomonas citri infection, 35 days after inoculation. To the left: an adaxial surface view under low level magnification. To the right: a thin section of the same leaf tissue pictured on the left (bars are $100 \mu \mathrm{m}$ ). Arrow labeled " $\mathrm{N}$ " indicates necrotic tissue; arrow labeled "B" indicates $X$. citri bacteria oozing from ruptured epidermis. 

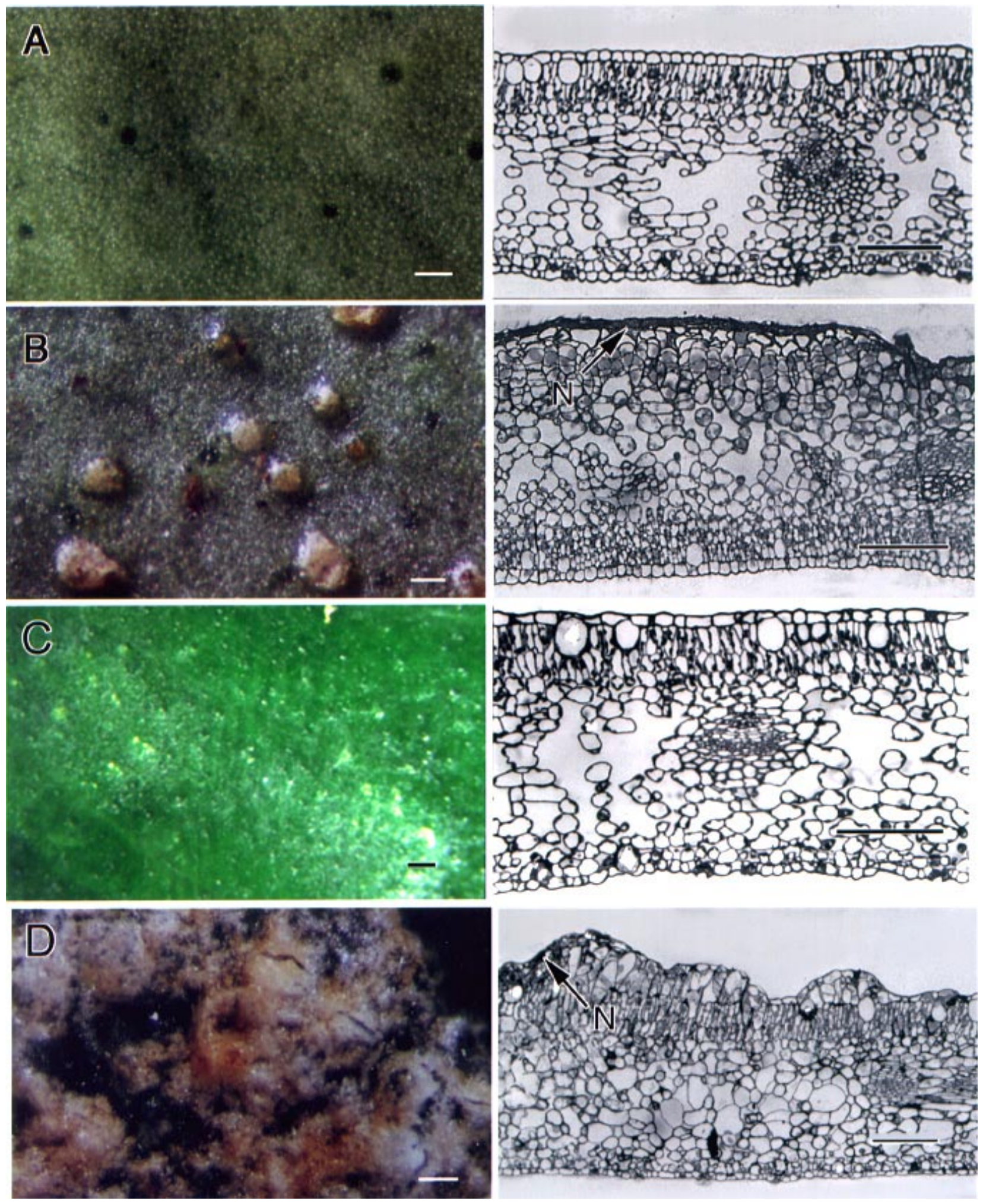

Fig. 2. Phenotypes elicited on Citrus sinensis (sweet orange) by pthA delivered into leaf cells and transiently expressed. Left column: surface views of the leaves with low level magnification. Right column: thin sections of the same leaf tissue pictured on the left (bars are $100 \mu \mathrm{m}$ in all photos). A, Control leaf tissue 3 weeks after biolistic bombardment with pBI221. B, Effect of biolistic delivery of pthA, 3 weeks after bombardment with pYD12.5. Shown are the increase in number of cells (hyperplasia), loss of free extracellular space (apoplast) in the spongy mesophyll, raised lesion areas, and necrotic epidermal layer of cells, compared with A. C, Control leaf tissue 45 days after inoculation with Agrobacterium tumefaciens GV2260. D, Effect of delivery of pthA via A. tumefaciens GV2260/ pYD 40.1, 45 days after inoculation. There are similarities with $\mathbf{B}$, and also an increase in volume of many mesophyll cells (hypertrophy), compared with $\mathbf{C}$, along with the hyperplasia and more confluent symptoms. Arrows labeled " $\mathrm{N}$ " indicate necrotic tissues. There are similarities with Figure 1, but the symptoms are quantitatively less severe and the epidermal layer is barely ruptured. 
However, several microbial avr genes can elicit an HR when expressed inside plant cells carrying specific resistance $(R)$ genes (Gopalan et al. 1996; Tang et al. 1996; Scofield et al. 1996; Van den Ackerveken et al. 1996; de Feyter et al. 1998; Stevens et al. 1998). Both $a v r B$ and $a v r R p t 2$ cause cell death

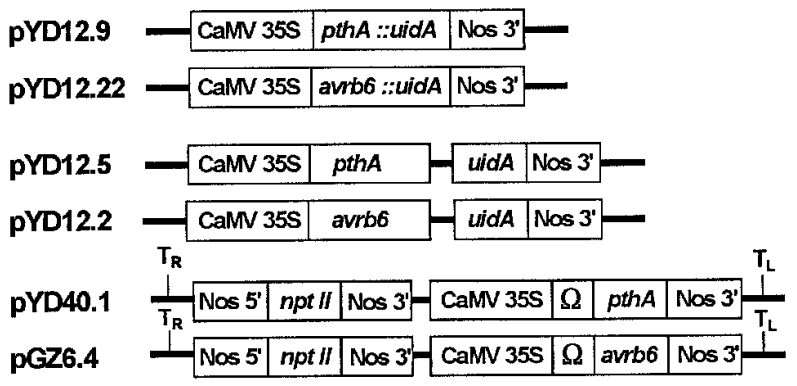

Fig. 3. DNA constructions used in the transient expression assays. pthA was cloned from pZit45 into pUC118 with a uracil DNA glycosylase (UDG) polymerase chain reaction (PCR) technique (Nisson et al. 1991) that allowed creation of multiple cloning sites at strategic locations. The resulting clone pYD9.3 had EcoRI/XbaI and HindIII/BglII sites immediately flanking the $p t h A$ coding region. For transient expression in plants, the pthA and avrb6 coding regions were recloned into pBI221 (CLONETECH Laboratories, Palo Alto, CA) such that they would be expressed from the $35 \mathrm{~S}$ promoter, and also creating translational fusions with uidA with the $X b a I$ and $B g l I I$ restriction sites (pYD12.9 and pYD12.22, respectively) and transcriptional fusions with uidA with the XbaI and SmaI sites (pYD12.5 and pYD12.2, respectively). These genes were also cloned into the Agrobacterium tumefaciens binary vector pB48.212 (Li et al. 1994), forming pYD40.1 and pGZ6.4. Left and right border sequences of T-DNA: represented by $T_{L}$ and $T_{R}$. Nos, nopaline synthase. A, translational enhancer region from tobacco mosaic virus.

Table 1. Symptoms elicited by pthA and avrb6 in Xanthomonas citri and when delivered directly into sweet orange leaf cells ${ }^{\mathrm{a}}$

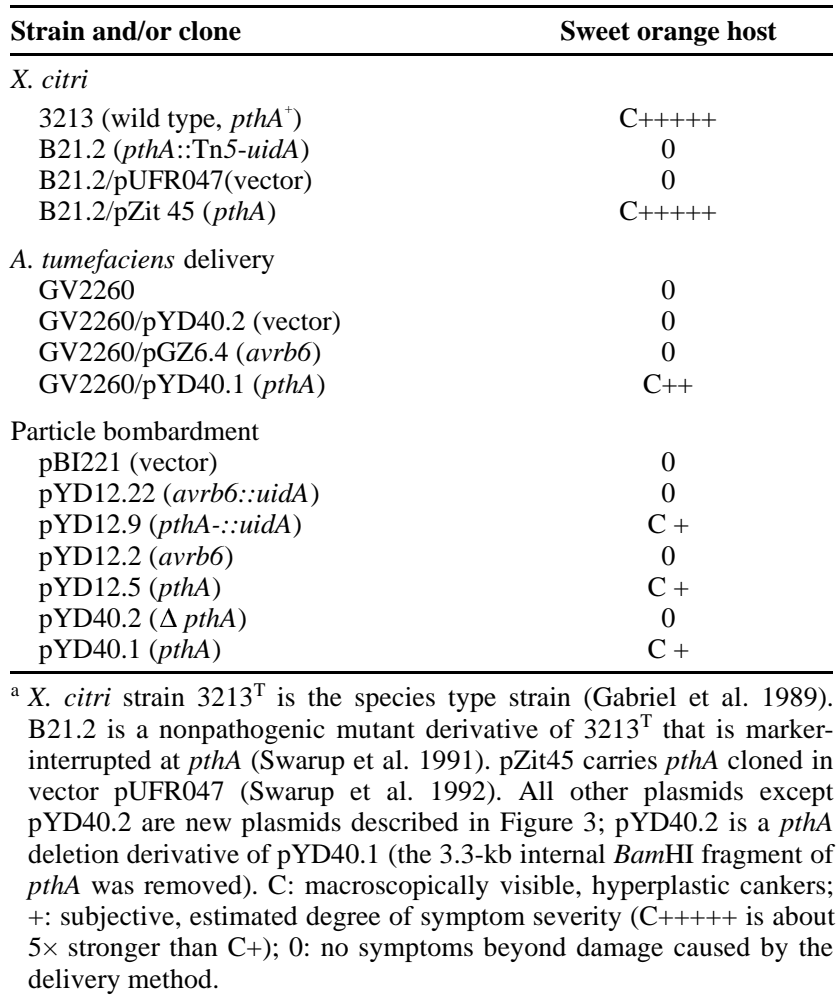

and necrosis in plants evidently lacking cognate $R$ genes, thus suggesting a possible role for these $a v r$ genes in pathogenicity (Gopalan et al. 1996; McNellis et al. 1998). Gene pthA belongs to a large avirulence/pathogenicity family-the avrBs3/pthA gene family (Leach and White 1996) - that is widespread in the genus Xanthomonas. Members are conserved among all strains of some species and/or pathovars, including all strains causing cotton blight, rice blight, and common bean blight (Gabriel 1997). A causal role in pathogenicity for members of the gene family has also been demonstrated with cotton blight (Yang et al. 1996) and is strongly suggested for rice blight (Leach and White 1996).

For either pathogenicity or avirulence phenotypes to be elicited by most bacterial plant pathogens, including X. citri, a functional type III protein secretion system encoded by hrp (hypersensitive response and pathogenicity) genes is required (He 1998; Alfano and Collmer 1997). Function of pthA in X. citri for either pathogenicity or avirulence is hrp dependent (Yang and Gabriel 1995a). Type III protein secretion systems are essential for pathogenicity of many bacteria, including Yersinia pestis (black plague) and enteropathogenic Yersinia spp., Shigella spp., and Escherichia coli (Hueck 1998). The type III secretion system is a host cell contact-dependent, toxic protein injection device in mammalian pathogens (Silhavy 1997). The system appears to work similarly in plant pathogens, but fewer genes are known to be involved and there may be several important differences (He 1998). After PthA was found to encode functional NLS sequences, the protein was proposed as a candidate effector signal secreted by the X. citri hrp system directly or indirectly into the plant cell (Yang and Gabriel 1995a; Gabriel 1997). Taken together, these results provide strong indirect evidence that PthA is secreted from $X$. citri and functions inside the plant cell. Although A. tumefaciens causes crown gall disease by transfer of a piece of DNA into plant cells, this represents the first report of a bacterial pathogen that causes disease by transfer of a protein signal into the plant cell.

\section{ACKNOWLEDGMENTS}

We wish to thank L. C. Hannah and D. Pring, University of Florida, and R. de Feyter, CSIRO, Canberra, for critical comments on the manuscript. Florida Agricultural Experiment Station Journal Series no. R06379 .

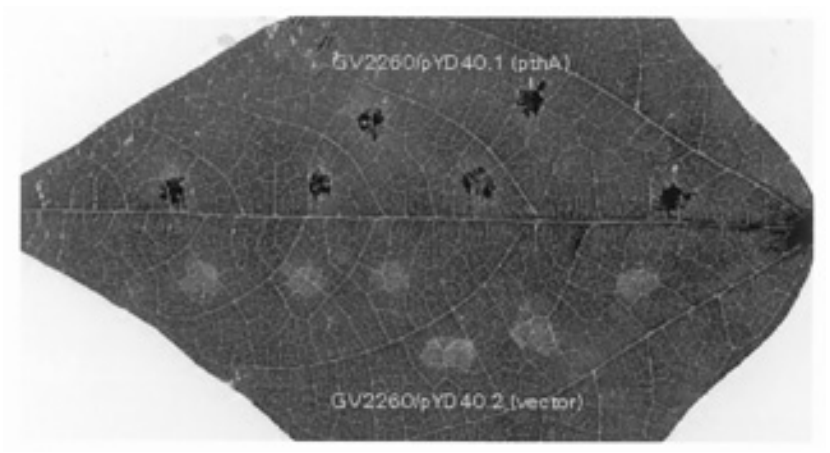

Fig. 4. Hypersensitive response (HR) elicited by pthA in Phaseolus vulgaris (common bean) cv. California Light Red leaf after inoculation with Agrobacterium tumefaciens GV2260/pYD40.1. 


\section{LITERATURE CITED}

Alfano, J. R., and Collmer, A. 1997. The type III (Hrp) secretion pathway of plant pathogenic bacteria: Trafficking harpins, Avr proteins and death. J. Bacteriol. 179:5655-5662.

de Feyter, R., McFadden, H., and Dennis, L. 1998. Five avirulence genes from Xanthomonas campestris pv. malvacearum cause genotype-specific cell death when expressed transiently in cotton. Mol. Plant-Microbe Interact. 11:698-701.

Gabriel, D. W. 1997. Targeting of protein signals from Xanthomonas to the plant nucleus. Trends Plant Sci. 2:204-206.

Gabriel, D. W., Kingsley, M. T., Hunter, J. E., and Gottwald, T. R. 1989. Reinstatement of Xanthomonas citri (ex Hasse) and X. phaseoli (ex Smith) and reclassification of all $X$. campestris pv. citri strains. Int. J. Syst. Bacteriol. 39:14-22.

Gopalan, S., Bauer, D. W., Alfano, J. R., Loniello, A. O., He, S. Y., and Collmer, A. 1996. Expression of the Pseudomonas syringae avirulence protein AvrB in plant cells alleviates its dependence on the hypersensitive response and pathogenicity (Hrp) secretion system in eliciting genotype-specific hypersensitive cell death. Plant Cell 8: 1095-1105.

Graham, J. H., and Gottwald, T. R. 1991. Research perspectives on eradication of citrus bacterial diseases in Florida. Plant Dis. 75:11931200.

Gray, D. J., Hiebert, E., Compton, M. E., McColley, D. W., Harrison, R. J., and Gaba, V. P. 1994. Simplified construction and performance of a device for particle bombardment. Plant Cell 37:179-184.

Greenberg, J. T. 1997. Programmed cell death in plant-pathogen interactions. Annu. Rev. Plant Physiol. 48:525-545.

He, S. Y. 1998. Type III protein secretion systems in plant and animal pathogenic bacteria, Annu. Rev. Phytopathol. 36:363-392.

Hueck, C. J. 1998. Type III protein secretion systems in bacterial pathogens of animals and plants. Microbiol. Mol. Biol. Rev. 62:379-433.

Kapila, J., DeRycke, R., Van Montagu, M., and Angenon, G. 1997. An Agrobacterium-mediated transient gene expression system for intact leaves. Plant Sci. 122:101-108.

Leach, J. E., and White, F. F. 1996. Bacterial avirulence genes. Annu. Rev. Phytopathol. 34:153-179.

Li, T. Y., Tian, Y. C., Qin, X. F., Mang, K. Q., Li, W. G., He, Y. G., and Shen, L. 1994. Transgenic tobacco plants with efficient insect resistance. Sci. China 37:1479-1488.

McNellis, T. W., Mudgett, M. B., Li, K., Aoyama, T., Horvath, D., Chua, N. H., and Staskawicz, B. J. 1998. Glucocorticoid-inducible expres- sion of a bacterial avirulence gene in transgenic Arabidopsis induces hypersensitive cell death. Plant J. 14:247-257.

Nisson, P. E., Rashtchian, A., and Watkins, P. C. 1991. Rapid and efficient cloning of Alu-PCR products using uracil DNA glycosylase. PCR Methods Appl. 1:120-123.

Scofield, S. R., Tobias, C. M., Rathjen, J. P., Chang, J. H., Lavelle, D. T., Michelmore, R. W., and Staskawicz, B. J. 1996. Molecular basis of gene-for-gene specificity in bacterial speck disease of tomato. Science 274:2063-2065.

Silhavy, T. J. 1997. Death by lethal injection. Science 278:1085-1086

Starr, M. P. 1983. The Genus Xanthomonas. Pages 742-763 in: The Prokaryotes: A Handbook on Habitats, Isolation, and Identification of bacteria. M. P. Starr, ed. Springer-Verlag, New York,

Stevens, C., Bennett, M. A., Athanassopoulos, E., Tsiamis, G., Taylor, J. D., and Mansfield, J. W. 1998. Sequence variations in alleles of the avirulence gene avrPphE.R2 from Pseudomonas syringae pv. phaseolicola lead to loss of recognition of the AvrPphE protein within bean cells and a gain in cultivar-specific virulence. Mol. Microbiol. 29:165-177.

Swarup, S., de Feyter, R., Brlansky, R. H., and Gabriel, D. W. 1991. A pathogenicity locus from Xanthomonas citri enables strains from several pathovars of $X$. campestris to elicit cankerlike lesions on citrus. Phytopathology 81:802-809.

Swarup, S., Yang, Y., Kingsley, M. T., and Gabriel, D. W. 1992. A Xanthomonas citri pathogenicity gene, pthA, pleiotropically encodes gratuitous avirulence on nonhosts. Mol. Plant-Microbe Interact. 5:204213.

Tang, X., Frederick, R. D., Zhou, J., Halterman, D. A., Jia, Y., and Martin, G. B. 1996. Initiation of plant disease resistance by physical interaction of AvrPto and Pto kinase. Science 274:2060-2063.

Van den Ackerveken, G., Marois, E., and Bonas, U. 1996. Recognition of the bacterial avirulence protein AvrBs3 occurs inside the host plant cell. Cell 87:1307-1316.

Yang, Y., and Gabriel, D. W. 1995a. Xanthomonas avirulence/pathogenicity gene family encodes functional plant nuclear targeting signals. Mol. Plant-Microbe Interact. 8:627-631.

Yang, Y., and Gabriel, D. W. 1995b. Intragenic recombination of a single plant pathogen gene provides a mechanism for the evolution of new host specificities. J. Bacteriol. 177:4963-4968.

Yang, Y., Yuan, Q., and Gabriel, D. W. 1996. Watersoaking function(s) of XcmH1005 are redundantly encoded by members of the Xanthomonas avr/pth gene family. Mol. Plant-Microbe Interact. 9:105-113. 